\title{
CASE OF RETROCORNEAL PANNUS WITH GLAUCOMA*
}

\author{
BY \\ J. PRIMROSE \\ Oldchurch Hospital, Romford
}

\section{Case Report}

The patient, a 57-year old housewife, presented on April 10, 1964, with a history of the left eye being misty for about six months and of having an ache over it for some weeks. There was no history of inflammation or injury. She had had glasses for some years and had been examined twice for new glasses in the last six months without any comment having been made. There was no family history of glaucoma. Visual acuity with a small correction was right $6 / 9$, left $6 / 18$.

The right eye appeared at first glance to be normal with a healthy fundus and a tension of $20 \mathrm{~mm}$. Hg Schiötz, but some fine vessels were just visible, which were shown by slit-lamp examination to be on the posterior surface of the cornea. There were no interstitial vessels and the cornea was of even thickness without any stromal opacity (Fig. A). The anterior chamber was deep, the iris appeared normal, and there were no posterior synechiae or signs of previous inflammation. The retrocorneal vessels were seen on gonioscopy to arise at the base of the angle, mainly from the major arterial circle, and an occasional one bridged across the angle from iris to cornea by means of an anterior synechia. There were other anterior synechiae without apparent vessels, but the synechiae did not obliterate more than 15 per cent. of the angle, which elsewhere was open and looked healthy (Fig. C).

The left eye showed some corneal oedema, a tension in excess of $58 \mathrm{~mm}$. Hg Schiötz, and a cupped disc with marked field loss. There were retrocorneal vessels similar to those seen in the right eye, and again a complete absence of interstitial trouble or inflammatory signs (Fig. B). The vessels were no more numerous than in the right and they were not particularly well filled in either eye, but a steady trickle of blood along them could easily be seen in both eyes. The angle, however, showed many more peripheral anterior synechiae (about 50 per cent.). In the spaces between the synechiae the angle was open and the origin of some of the vessels could be seen to be as in the right eye. The anterior chamber was as deep as in the right eye. Miotic therapy was instituted for the left but even with acetazolamide the tension in the left eye did not remain below $40 \mathrm{~mm}$. Hg Schiötz. A left drainage operation (Scheie) was performed on May 6, 1964, without encountering undue bleeding, and the post-operative course was uneventful. The eye drains freely. When last seen on November 6, 1964, the visual acuity was $6 / 18$ and the tension less than $5 \mathrm{~mm}$. Hg Schiötz. The vessels remained unchanged.

The right eye is being kept under observation. The tension has not exceeded $21 \mathrm{~mm}$. Hg Schiötz $(18 \mathrm{~mm}$. $\mathrm{Hg}$ applanation) and the outflow is reasonable $(\mathrm{C}=0 \cdot 17)$. The disc and field remain normal. Serology was, of course, tested and found to be negative.

\section{Discussion}

It seems obvious that the left glaucoma arises from obliteration of a major part of the angle by the peripheral anterior synechiae. The vessels, although sharing in the obliteration, would have little effect on blocking the drainage, as the other eye

\footnotetext{
* Received for publication December 12, 1964.
} 
A

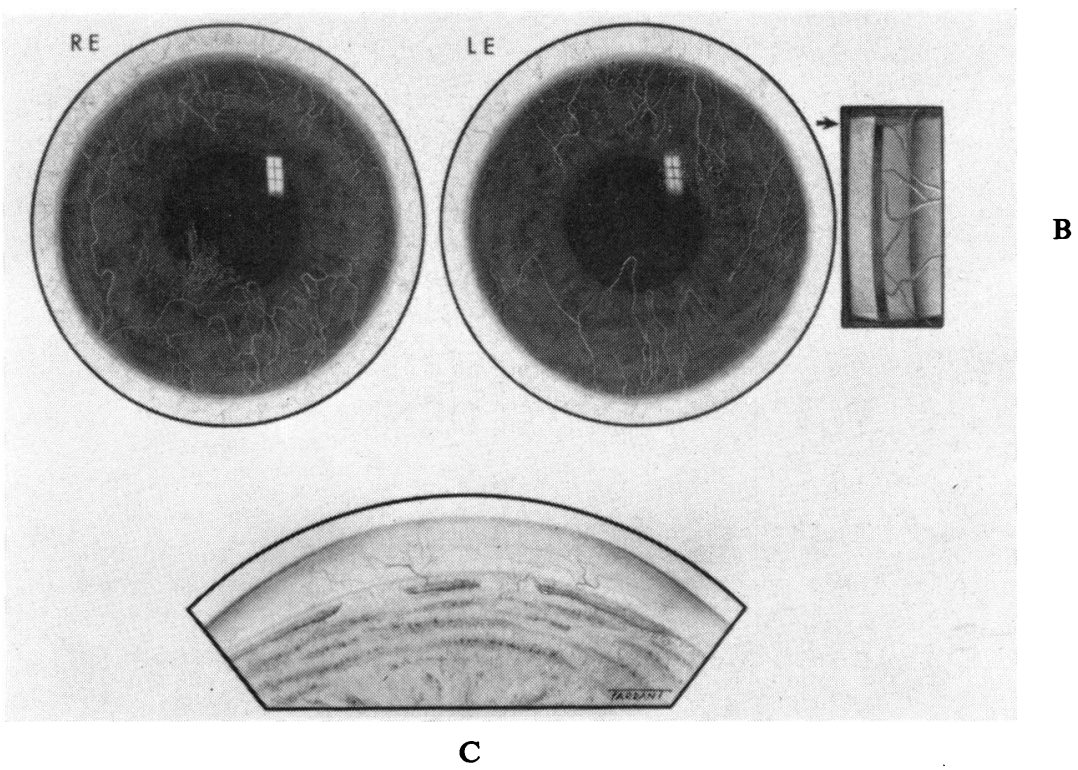

FIG.-A, Front view of right eye showing retrocorneal vessels. B, Front view of left eye showing retrocorneal vessels and mild epithelial oedema; inset shows location of retrocorneal vessels in slit-lamp view. C, Gonioscopic appearance showing peripheral synechiae and origin of some retrocorneal vessels.

had not become glaucomatous in spite of just as many vessels though many fewer synechiae. Indeed, I wonder if the vessels might have been a compensatory growth to help absorb aqueous or to nourish the cornea. They did not, however, resemble the new-vessel formation which occurs in thrombotic glaucoma or diabetic rubeosis, nor are retrocorneal vessels described in those conditions. The only article I have found on retrocorneal vessels is by Krückmann (1911), which refers to new-vessel formation in the weeks following traumatic hyphaema and associated with the development of glaucoma. In the absence of any signs or history of previous inflammation or injury it is probable that both the vessels and the peripheral synechiae are developmental residues. I have not seen such vessels before, nor found any references to them in standard works on embryology. They are not mentioned in Sugar's (1951) extensive classification of the causes of glaucoma. One might have expected a presumably congenital cause to have manifested itself earlier in life, yet an eye, otherwise healthy, can survive 50 per cent. obliteration of the angle for many years. The patient reported here had not previously had any examination more than is required for the supply of glasses.

\section{REFERENCES}

Krückmann, E. (1911). Ber. ophthal. Ges. Heidelberg, 37, 16.

SugAR, H. S. (1951). "The Glaucomas". Hoeber, New York. 